\title{
THE PROBLEMS THAT ARE FACING THE ELECTRICAL ENGINEER OF TO-DAY AND THE QUALITIES OF MIND AND CHARACTER WHICH ARE NEEDED TO MEET THEM.
}

BY J. G. WHITE.

Since the title assigned for this paper contains more than one per cent. of the total number of words allotted, there seems little room to speculate as to the problems confronting us.

To some engineers apparently the one and only problem is that of salary, while for others the greatest problem is to find men who can and will earn large salaries.

Other problems range from figuring the proper size of an electrical conductor or tracing out a telephone circuit up to the highest speculative imaginings of which the human mind is capable, such as those suggested by the recent statements of Prof. Crooke's, Prof. and Madame Curie and others, regarding the atomic theory.

We are now to d that each atom, formerly considered indivisible, is a whole stellar system, composed of a tremendous number of absolutely identical units, all in orbital motion.

We are further told that of these identical units or ions,.an atom of oxygen contains 11,200; an atom of gold 137,200; an atom of radium, 120,000; and so on.

Who can delineate the problems which will be presented by this new theory, or by the strange properties of the recently discovered radium and other radioactive substances?

A recent article on this new development says: "Chemistry has in fact become the astronomy of the infinitesimal. One is led to wonder then if the earth and the other planets are not mere ions forming a single atom of a higher universe, where perhaps they constitute a speck of dust that worries the careful housewife in the world next above us." 
As, however, this is a body of educators and engineers rather than of astronomers and philosophers, may it not be well to avoid speculation and be content during the brief time at our disposal with what might be called a " plain 3 per cent. investment?"

The qualities of mind and of character needed by the electrical engineer of to-day are too well-known to need to be specified.

He should be accurate in his calculations, thorough in his investigations, logical in his deductions, lucid and concise in his statements.

He should have untiring energy, an alert mind, abundant initiative, and reasonable self-confidence.

He should be absolutely honest in all his dealings, truthful in all statements, loyal to his clients, faithful to his employer's interests, considerate of his subordinates, diplomatic in his negotiations and tactful in all his relations.

However, instead of attempting to rear a structure on the foundation of the text assigned to us, may we not rather use it as a spring-board from which to vault into the general field under discussion to-day?

This might be summarized under the title, "What education should the electrical engineer of to-day have."

In entering this field, I realize that I may be trespassing on the preserves and vested rights of Messrs. Gherardi, Osborne and Johnston, whose papers are to follow:

In that case I hope these gentlemen will follow the example of the beasts in Kipling's Jungle Stories, and wish me " Good Hunting."

Irrespective of this, there are a few points in the education of an engineer which are so important that it would probably do no harm if they should be repeated and urged by every one of the men to whom papers for to-day's session were assigned.

One of these points is well covered by Mr. Johnston's paper, " Engineering English," the great importance of which is further emphasized in the latter part of this paper.

As is frequently remarked, this is the age of great industrial combinations and of specialists. Not satisfied with this, the specialists now specialize. The engineering field was formerly divided into the two general classes of military and civil engineers. From the latter gradually developed marine, mining and mechanical engineering, and as an offshoot from this last branch, there was recently added electrical engineering. Civil engineers to-day are sub-divided into such classes as hydraulic engineers, bridge engineers, railroad engineers, etc. We also find that electrical 
engineers are classified as telegraph engineers, electric light engineers, electrochemical engineers, telephone engineers, etc.

A few years ago many of us would have supposed that the problems of the telephone engineer were those of a high-class artisan and that they would consist largely of trying to unravel tangled cobwebs of fine wires, and to understand and to be able to operate mazes of signalling, connecting and protecting devices. A member of the Institute of Electrical Engineers, who is the head of the electrical engineering school in a prominent university, remarked not long ago that he never appreciated the importance of the telephone engineer until he saw one of the particularly well-known members of the profession decline a salary of $\$ 25,000$ a year. The professor further stated that ever since then he has wished he knew enough to be a telephone engineer.

In the early days it was thought that a room of almost any shape and size, with a couple of empty boxes for seats, and a switchboard of primitive design and construction was all that was needed to make a telephone exchange. The City of New York had in 1894 about 10,000 telephones or "stations"; in 1900 the number was about 45,000 ; at present, the number is in the neighborhood of 100,000 , an increase of 1,000 per cent. in nine years, and by 1910 it is estimated the number will be perhaps 300,000 . These figures are understood to be exclusive of desk or other extension sets.

Owing to the wonderful growth of their business, telephone companies now erect buildings specially designed to meet the requirements of their exchanges, and a telephone engineer must know something of architecture, the strength of materials and other factors entering into modern steel building construction, and many other subjects which should be a part of a broad engineering education, but which are not ordinarily supposed to come within the province of a telephone engineer, as narrowly applied:

It is at least equally important that other engineers who have specialized and must know well some part of the field of engineering should likewise have a general knowledge of the sciences and of the broad underlying principles of engineering, based on a thorough mastery of elementary mathematics and supplemented by some study of languages, history, civics and other studies of general educational value.

The question naturally arises, how can the engineering student 
possibly obtain a satisfactory knowledge of all of these important subjects? Much of his special knowledge must be acquired after he has commenced the practice of his profession. If unusually energetic and capable, all or any part of his education may be gained after he enters professional life, but it is preferable that his broader education be well started during his school years. For a considerable time it has been clearly recognized that law and medicine require, for general and special study, more time than is possibly available in the ordinary college course of four years. The well-educated lawyer of to-day takes a thorough preparatory course, four years in college, and three, or at least two, years in law school, and after this is likely, if he can afford it, to take one year abroad or in some special post-graduate work. The welleducated physician of to-day after regular and preparatory courses, spends three years in medical college, and if possible, one year in foreign study, and then is likely to devote several years to hospital work, before attempting to engage in the general practice of his profession.

If lawyers and doctors can afford the time and money necessary to get such educations, should not engineers, in view of the very wide range of subjects with which they must now be reasonably familiar, adopt a similar plan? The decision of the question will have to be made individually by the young men themselves, important factors being the time and money available for educational purposes.

It is well to remember, however, that more important than a knowledge of any study, or group of studies, is the ability to master thoroughly any subject of which a knowledge is desired.

In education especially, quality is more important than quantity. A thorough mastery of arithmetic and algebra is better than a mere " pass grade " knowledge of these and all the higher mathematics, which is then ordinarily soon forgotten.

It is better never to have seen the inside of a Latin, French or German gramimar, and to use correct English, than to have the ordinary three or four years " translating knowledge" of all three of these foreign languages and still say, "I seen."

As in nearly all practical engineering problems, this one of engineering education can perhaps be best set forth by arranging a balance sheet showing the credit and debit sides. Against the extended education we have expense involved, time necessary before the earning period is reached, time required for general study which might be devoted to mastering some special branch 
of engineering, thus more quickly insuring a comfortable salary, danger to health if too much study is crowded into a given period, etc. On this side also we have the danger that by widely extending the field of endeavor we may produce a student rather than an engineer, or that the work may be superficial. The $i m-$ portance of thoroughness is supreme.

This implies also that the education of the engineer must develop not a dreamer, but a worker, thoroughly competent in his sphere, whether great or small.

It is better for the world and for the man that he should be a high class mechanic or artisan, with a good common school education, than that he should be nominally an "engineer," having a smattering of many subjects, and ekeing out an existence amongst more competent fellows.

It is better for him never to have been inside a college, but to have commenced at wheeling ashes and become a sood electric light superintendent, than that he should "drag " through college and university, take master's and doctor's degrees and become an incompetent college professor. His social status may not be as high, but he will be a more useful man.

On the credit side of the extended education we have, first, the direct satisfaction to be had from its possession and the ability to enjoy on even terms the society of educated people.

Secondly, there is the practical use to which this knowledge can be put.

Thirdly, and more important than the knowledge actually acquired, is the learning how to know a subject, and where or in what direction to look for information specifically wanted.

Fourthly, there is the certainty that with equal industry and attention to his work, the young engineer of ability with a broad education will ultimately take higher rank in his profession and be more successful in business.

The qualified phrase, "young engineer of ability" is used advisedly. The encineer of ordinary or less than ordinary ability, will, in practical life, accomplish most by not attempting to have his education cover too wide a field, and learning some special departmient thoroughly.

A prosperous market gardener is more to be envied than a poor farmer.

If a young man will take for his motto " thoroughness," and, in planning his list of studies, will include first those of prime importance, and then add those of decreasing importance until 
all his available time is occupied he will be planning most wisely. Ordinarily the young man will not be able to arrange a course entirely to suit his individual requirements, but he can use the method above suggested to help him in deciding as between various courses offered. The choice should, when time and mental capacity make it possible, be in favor of a broad general education, supplemented by thorough technical training. This may, and frequently will, lead to a general college course to be followed by a technical course of two or more years.

The writer recently knew of two groups of men who were each looking for an able street railway manager, and who were willing to pay in each instance a salary of $\$ 25,000$ per annum. The man who happened to be offered both of these positions is said to have been for 12 years a street car conductor. This is no proof that an engineering education is valueless. It is, however, conclusive proof of the superior importance of good business judgment and the ability thoroughly to master a given subject, which in this instance happened to be street railway operation and management.

People are to-day looking for engineers and would gladly pay salaries of $\$ 6,000$ to $\$ 10,000$ per annum for men of exactly the right qualifications. It would be easy to find hundreds of men who have had all the necessary general education, and scores who have had as well all the needed technical training. The questions which are asked, however, are such as the following:

Has he good business judgment?

Has he tact?

Has he the mental capacity and breadth to develop into a "big man?"

Is he diplomatic, with ability to negotiate?

Is he initiative, without being erratic?

Will he get results?

We might divide the studies which are worthy the attention of the electrical engineer into four general classes. Individual opinions will necessarily differ widely as to the studies which should come within each class. Some will want to increase and others diminish the total number. In any event, the student should attempt studies of the relatively less important classes only in case he has already mastered thoroughly, or is sure of so mastering, the more important studies.

In the first class we may put those studies which will teach to think clearly and express lucidly, which will teach how to learn, and which will give a comprehensive knowledge of the fundamental 
facts and principles underlying his profession. These should be learned most thoroughly, and would include English, arithmetic (mental and written), algebra, geometry and trigonometry, chemistry, physics (especially mechanics), general knowledge of principles of electrical engineering, practical ethics.

The second class may include some subjects which will especially tend further to develop clear thinking and clear writing, some which will further increase the knowledge of the general principles of his profession, and some which will give knowledge that will be professionally and commercially useful. This class includes: Calculus and vectors, surveying, Latin (usual preparatory course) French (speaking and reading-not translating knowledge of), electrochemistry, advanced engineering studies, business law, general principles of modern accounting, civics.

The third class may include some subjects which are likely to be of direct professional or commercial use, and others, the study of which will be of general educational value. This class includes: Spanish, geology, physiology and temporary care of injured; logic, quaternions and subjects which are studies of engineering details rather than of general principles, etc.

The fourth class may include those studies which will help in rounding out the education of the man rather than in furnishing the essential equipment of the engineer. This class includes: Mineralogy, botany, zoology, history, political economy, mental and moral philosophy, art, music, etc.

The third and fourth classes of subjects are useful to round out and complete the foundation and frame work provided by the first and second classes, but should not be indulged in at the expense of the relatively more important. A few non-technical subjects merit individual mention.

ENGLISH.

President Butler, of Columbia University, is reported to have said: "The first two evidences of an education are correctness and precision of speech, and refined and gentle manners." The latter must be acquired almost entirely at one's home and from contact with one's associates. The correct speech must be acquired largely in the same way, but may be learned to a considerable extent, in the preparatory schools and in the college or university. There is nothing more important for the young engineer to learn than " the skilful and correct use of language, whether to state a fact or convey an idea," understanding that " clear thinking precedes clear speaking." 
English should be taught from beginning to end of the preparatory school work, and also from beginning to end of the college course. In order to have this drill continue throughout the college course, it may be necessary to have a considerable part of the training incorporated into the writing of laboratory reports, examination papers and other similar documents. Is this not feasible? Whether done in this way or not, the training should be continuously maintained.

\section{Arithmetic and Algebra.}

More attention may well be paid in the preparatory schools to algebra and arithmetic, especially mental arithmetic. A comprehensive understanding of algebra is most useful to the engineer both in his later studies and in practical work. Mental arithmetic provides both good mental exercise and equipment.

We sometimes hear engineers, as well as others, speak of the " poetry of motion." Many of our profession seem to understand this, only as applied to the slide rule. It is unnecessary, and is frequently annoying to have an engineer who is drawing a salary of several thousand dollars per annum pull out his slide rule, and, after some considerable manœuvring, announce that " 5 times $4 \frac{1}{2}$ is about 22 ," or that " two tons of rails at $\$ 33$ per ton will cost about $\$ 65$."

\section{SURVEYING.}

During the college course it would seem advantageous even for the electrical engineer to devote a moderate amount of time to the study of the various methods of surveying now practised. These can be quickly understood if the student has thoroughly mastered his arithmetic, geometry and trigonometry, and a general knowledge of surveying is very likely to be useful in practical work. The summer spent on railroad location and construction will help develop one's physique, teach one to read and fully appreciate a profile, give a little knowledge of construction costs and methods, and give other knowledge which one will probably find useful in both field and office. A summer so spent will in after life be remembered as time well and profitably occupied.

\section{French and Latin.}

French and Latin are included in the second class, because of the mental training and polish to be gained by their study. Some knowledge of Latin will greatly assist in thoroughly mastering English, and is in this respect more useful than the study of German. 
A knowledge of French which will enable the young engineer to speak and read with ease is strongly recommended. The educated people of Mexico, South America, Russia and other countries speak French, and as this for centuries has been the polite and diplomatic language of the world, the advantages to be derived from mastering it are likely to be not only educational and social, but commercial as well.

On the contrary, there is little prospect that American engineers can practise their profession profitably in Germany or German-speaking countries. Nearly all important scientific papers are now promptly translated into English, and included in the technical press or publications of the various scientific and engineering societies. In consequence, there is no longer any special need of the engineer knowing any foreign languages for the sake of keeping advised as to the progress made in the work of his profession.

The general educational value of learning one modern language seems about equal to that to be gained from learning another. Consequently, the social and commercial advantages of French give it first place for the American engineer.

\section{Spanish.}

The study of a second modern language should be undertaken only in case the first can be spoken fluently. Then it would seem that Spanish is the best language to learn. Having studied Latin and French, Spanish should be very easily acquired.

The development of Porto Rico, Cuba, the Philippines, Mexico, the Central and South American countries, will probably afford many opportunities for the engineers of the coming generation, and to these a knowledge of Spanish would be of great value.

\section{Engineering Studies.}

The time devoted to various engineering studies in Class 1 , as well as in Class 2, must depend largely on the facilities of the college attended, and the special work for which it is intended to prepare. It would be quite useless to attempt to discuss the relative importance of the purely technical studies in the time at our disposal, or to attempt to arrange any detailed plan of technical work.

\section{Business Training.}

Somewhere in the general course there should be included a moderate amount of training in modern business methods and practices. There is no more reason for the engineering graduate being utterly ignorant of even the most elementary 
knowledge of business practices than that he should know absolutely, nothing of geography.

\section{Accounting.}

All engineering students should have some reasonable training in accounting, so that they would not be entirely ignorant and without power of speech if, after beginning the practice of their profession, they are asked some elementary questions about the annual report of a street railway, electric light or manufacturing company.

\section{Business Law.}

A moderate amount of time should also be devoted to the study of fundamental principles of business and corporation law. An engineer, in practice, should at least be able to draw a contract which will be legal and explicit.

In General.

A modern engineer is dependent for his success largely on the financier. If the engineer does not know that bonds should pay interest, and that stocks, if possible, should pay dividends and has no conception of the difference between a stock certificate and a promissory note, the financier is likely to form an undeservedly low opinion of the engineer's technical knowledge.

If a young engiener will have before him constantly the ultimate and best interests of his employer, will endeavor always to be tactful and never unnecessarily to irritate, will-without flattery-say only what is pleasant, unless right demands a plain statement of an unpleasant truth, then his advance will surely be more rapid than if these things are forgotten or neglected. The importance of these things should be pointed out and frequently emphasized by educators.

The techincal problems which face the engineer are certain to be recognized as they come up. Too frequently the importance of problems connected with one's business and social relations with employers, fellow employees and others are not appreciated. These deserve careful and persistent study. Their correct solution and an accurate appreciation of the proper proportion of things, constitute business sagacity. The paramount importance of such matters should be repeatedly impressed on students and they should be led to understand thoroughly that their satisfactory solution will be rewarded not only by a pleasanter life during working, hours, but also by increased esteem and greater business success. 